\title{
Development, Implementation and Evaluation of Educational Package for Controlling Metabolic Syndrome Components: a quasi-experimental trial in Iran
}

\author{
Afsaneh Aein \\ Iran University of Medical Sciences \\ Negar Omidi ( $\square$ negar.omidi@gmail.com ) \\ https://orcid.org/0000-0002-9914-2935 \\ Farnaz Khatami \\ Tehran University of Medical Sciences \\ Shahed Samat \\ Tehran University of Medical Sciences \\ Mohammad Rafie Khorgami \\ Iran University of Medical Sciences
}

Research article

Keywords: Metabolic Syndrome, Educational Package, Life Style, Obesity, Triglyceride, Lipid

Posted Date: March 30th, 2020

DOI: https://doi.org/10.21203/rs.3.rs-19871/v1

License: (c) (i) This work is licensed under a Creative Commons Attribution 4.0 International License. Read Full License 


\section{Abstract}

Background This study was to develop, implement, and evaluate the impact of lifestyle education package in order to control metabolic syndrome components.

Methods Totally, 72 women and men aged 18-68 years with MetS from two health centers enrolled through randomized sampling to either intervention group who take usual care plus a 3-month lifestyle modification intervention or control group. Anthropometric indices, blood pressure, lipid profiles, and fasting blood glucose were assessed at baseline and after 3month.

Results Lifestyle modification program was associated with modest weight loss ( $2 \pm 0.4 \mathrm{~kg}, \mathrm{P}<0.001)$, a significant reduction in waist circumference $(2.3 \pm 0.9 \mathrm{~cm}, P<0.001)$ and hip circumference $(1 \pm 0.3 \mathrm{~cm}, P$ $<0.001)$, and a significant reduction in diastolic blood pressure $(5.3 \pm 1.4 \mathrm{~mm} \mathrm{Hg}, P<0.001)$ compared with baseline values in the intervention group. Also, $33.8 \%$ of the changes in metabolic syndrome components were attributable to educational intervention $(P<0.001, F=5.27)$.

Conclusions Lifestyle educational package had a significant effect on waist, hip circumference, and diastolic blood pressure at a 3-month. It is suggested that long-term educational interventions should perform to control other MetS components such as blood sugar and systolic blood pressure.

Retrospectively registered: This study was retrospectively registered in the Iranian website (www.irct.ir) for registration of clinical trials (IRCT20200212046470N1), on 2020-02-23.

\section{Background}

The metabolic syndrome (MetS) also called syndrome $\mathrm{X}$ is a constellation of metabolic risk factors that appear to directly feeds into the prevalence of atherosclerotic cardiovascular disease, and diabetes mellitus type II [1, 2]. MetS poses the worldwide prevalence ranges from $<10 \%$ to $>84 \%$, depending on method of defining MetS [3]. Many studies reported the spread of Mets in Iran from $8 \%$ to $43.6 \%$ based on various definitions [4]. The results of a comprehensive study in Iran over 12 years (from 2001 to 2013) indicated a $6.9 \%$ increase in the spread of metabolic syndrome [4-9]. Increase in the prevalence of MetS is possibly as a result of genetic factors, unhealthy lifestyle and environmental conditions [4-9]. These observed spread rates are higher than the predicted spread around the world, which is between $20 \%$ and $25 \%$ [10].

Studies demonstrated adequate knowledge on management and prevention of MetS would enable people's adaptation to healthy behaviors $[11,12]$. The lifestyle modification is the most efficient policy or strategy to manage metabolic syndrome. However, there is limited evidence of specific educational strategies [13, 14]. Studies have shown that usage of educational technologies such as multimedia communication and mobile increase the efficiency on lifestyle change [15]. Concomitant usage of virtual and video educational methods along with written material makes the method more effective, facilitates the comprehension of the subject and improves attitudes and adaptation to social and cultural contexts in individuals, encouraging more and better health behavior, and thus engaging people in active education[16-20]. In general, evidence of specific 
educational strategies for the long-term maintenance of lifestyle changes in controlling metabolic syndrome components is limited, and most have suggested mixed studies on educational methods[19].

The main target of the current study is to design, implement, and evaluate the impact of the lifestyle modification package in order to control metabolic syndrome components. The results of this paper would provide significant information to manage MetS in at-risk population.

This is a quasi-experimental study conducted with 72 participants (aged 18-68 years) with Mets according to International Diabetes Federation (IDF) definition from two health centers in Tehran, Iran in 2018.

\section{Methods}

\section{Study design}

This is a quasi-experimental study conducted with 72 participants (aged 18-68 years) with Mets according to International Diabetes Federation (IDF) definition [3] from two health centers in Tehran, Iran in 2018.

\section{Population; inclusion and exclusion criteria}

In a random sampling method, two centers selected from two different distinct in south of Tehran; 72 participants (36 participants in each group) enrolled in study. The intervention and control groups were not in touch with each other. The inclusion criteria were as follows: minimum age of 18 years old and existence of $\geq 3 / 5$ elements for metabolic syndrome including: 1 ) central obesity (men: $\geq 94 \mathrm{~cm}$, women: $\geq 80 \mathrm{~cm}$ waist circumference); 2) hypertension (systolic $\geq 130 \mathrm{mmHg}$, diastolic $\geq 85 \mathrm{mmHg}$ and/or anti-hypertensive treatment); 3) diabetes (fasting blood sugar (FBS) $\geq 100 \mathrm{mg} / \mathrm{dL}$ and/or anti-diabetic treatment); 4) elevated triglycerides(TG) ( $\geq 150 \mathrm{mg} / \mathrm{dL}$ ); and 5) low high-density lipoprotein (HDL) (men: $<40 \mathrm{mg} / \mathrm{dL}$, women: $<50$ $\mathrm{mg} / \mathrm{dL}$ ) and/or cholesterol-lowering treatment [3]. The exclusion criteria were hepatic diseases, hematologic diseases, renal failure (GFR $<30$ ), hypothyroidism, taking oral contraceptives, severe psychological illness, physical disability, cancer, type 1 diabetes, dementia, a level of education less than fifth grade, Immigration to another city and Changing in medications during study period.

\section{Intervention}

The purpose of providing a 3-month lifestyle modification program added to usual care was to promote motivation and awareness among this participation. In the development phase, the educational content extracted from the guidelines and discussed by five experts including two cardiologists, a Community medicine specialist, a health education specialist and a media expert. The media and messages pretested by interviewing 10 participants using a researcher-made checklist. In the implementation phase, the research objectives explained to eligible participants and informed consent obtained. The intervention group received educational package consists of a three months' schedul schedule (Appendix 1 \& Appendix 2). The control group received usual care by a physician in each visit (Figure 1).

\section{Anthropometric measurement}


It should be noted that the body weight was assessed in the fasting state without shoes and with light clothing by a Seca scale (Seca, Hamburg, Germany). Waist circumference was assessed to the nearest $\mathrm{cm}$ with the participants standing, at the level midway between the lower rib margin and the iliac crest.

\section{Blood pressure measurement}

Blood pressure was assessed three times by the same examiner, using a digital sphygmomanometer (Omron, JAPAN). It should be noted that this prose was measured after a 15-minute rest. The participants were asked to breathe out gently and relax during the measurement.

\section{Biochemical analysis}

Whole blood samples were collected from an antecubital vein in sitting position after a 12 hour fasting. FBS was assessed by Glucose oxidase (GOD) mechanism, total cholesterol (TC) and HDL cholesterol levels were specified by Trinder CHOD/POD End Point method. TG determined by GPO/POD method and LDL cholesterol measured by Friedewald formula [21]. Cutoff points were taken as follows: For TG, $\geq 150 \mathrm{mg} / \mathrm{dl} ; \mathrm{TC}, \geq 200$ $\mathrm{mg} / \mathrm{dl} ; \mathrm{HDL}$-cholesterol $<40 \mathrm{mg} / \mathrm{dl}$ in males and $<50 \mathrm{mg} / \mathrm{dl}$ in females; and LDL-cholesterol, $\geq 70 \mathrm{mg} / \mathrm{dl}[3$, 22].

\section{Statistical analysis}

Statistical analysis performed using the SPSS version 22.0 (SPSS, Chicago, IL). Variables presented as means $\pm S D$ or others as frequency. The Kolmogorov-Smirnov test, $t$-test, one way Manova and MannWhitney $\mathrm{U}$ tests were used for comparing variables between groups. The difference between the averages calculated by using Pair t- test and Independent t- test. Results considered statistically significant at $\mathrm{P}<0.05$.

\section{Results}

A total of 72 participants were recruited in this study (29.2\% were male, $70.8 \%$ were female). Participants were 46 years old on average, $98.6 \%$ were married and $72.2 \%$ had diploma. Baseline characteristics compared in Table 1. The anthropometric and metabolic profile changes over the three-month period depicted in Table 2. According to the results of one-way Manova analysis, changes in components of metabolic syndrome was significantly dependent on educational intervention $(F=5.27, p<.001$, partial $\eta 2=$ 0.338). $33.8 \%$ of changes in metabolic syndrome components were due to educational intervention and among these components, changes in the waist circumference and diastolic blood pressure were significant (Table 3).

\section{Discussion}

The results of our study revealed that combination of different educational methods include face-to-face education, pamphlet presentation, telephone text messaging, and educational films within 3 months were effective. 
Generally, the results of this study are consistent with Azizi and Amiri studies, which showed, healthy lifestyle intervention reduce the risk of MetS in both genders in short term [16, 23]. A similar study from Thailand undertaken by Chaiyasoot et al showed that a 3 months' lifestyle educational intervention in adults with obesity and metabolic syndrome resulted in in significant reduction in weight, waist circumference, blood pressure, and lipid profile [24].

Our Findings reflects that lifestyle intervention has modest efficacy in reducing weight. Weight loss is related with considerable improvements in the clinical abnormalities of MetS, such as blood pressure/glucose and lipid profile. Even a mild to moderate weight loss (2-7\% reduction) in 3 months may improve the metabolic profile, despite high BMI. However, the greater the BMI loss, the larger are the metabolic improvements [25, 26]. The results of this study demonstrate the potential benefits of using social media to assist overweight and obese patients. Consistent with other studies, educational intervention is effective in decreasing in waist circumference and waist-hip ratio $(p<0.001)[16,23,24]$.

Contrary to our results, DHIAAN and Islam etal. Study demonstrated no significant change in waist circumference $[27,28]$, however the reported differences between the groups could be considered clinically significant (difference= 8 inches, $p=0.39$ ), showing that the study may not have been powered, enoughly [29].

Although systolic blood pressure did not change significantly, mean arterial pressure and diastolic blood pressure decreased considerably $(p<0.001)$. Our findings are in agreement with studies that showed no significant change in the systolic blood pressure after educational intervention [27, 30, 31]. According to evidence, reducing diastolic blood pressure can be due to weight loss and a decrease in lipid profiles; however, long-term interventions need to control systolic blood pressure [32, 33].

In present study, FBS has no significant change in both group. The frequency of diabetes was considerably higher in control group ( $30 \%$ versus $8 \%)(p=0.017)$. Owing to the difference in frequency of diabetes, it is difficult to decide on the impact of education on fasting blood glucose. This finding emphasizes the need for ongoing support, long-term educational intervention to reduce fasting blood glucose level. Findings of the current study revealed that the three-month lifestyle intervention decreased the prevalence of MetS in both group, which are in line with Bright Bodies and other short-term intervention studies [23, 34, 35].

Technology (film and send an educational message) was found to be a valuable tool in achieving lifestyle change, but ineffective when compared with individual education method [15, 36, 37]. As shown in a systematic review, educational package, including face-to-face, pamphlet, film and message, were the most useful method for lifestyle modification in Mets. Furthermore, the results show that although one's knowledge on Mets and its prevention is necessary, it is not enough [29]. The study suggests that in order to promote lifestyle modification, it is not enough to provide sufficient information to participants, but individual beliefs should be considered. On the other hand, most of the care is provided at home.

\section{Study limitations}


Short duration of intervention and follow up is one of our limitations. The baseline characteristics were not match in two groups.

\section{Conclusion}

Lifestyle educational package had a significant effect on waist and hip circumference, and diastolic blood pressure at a 3-month. It is suggested that long-term educational interventions should be performed to control other MetS components such as blood sugar and systolic blood pressure.

\section{Abbreviations}

MetS: Metabolic syndrome

IDF: International diabetes foundation

FBS: Fasting blood sugar

TG: Triglycerides

HDL: Low high-density lipoprotein

LDL: Low-density Lipoprotein

TC: Total cholesterol

SBP: Systolic blood pressure

DBP: Diastolic blood Pressure

MAP: mean arterial pressure

GFR: Glomerular filtration rate

GOD: Glucose oxidase

WC: Waist circumference

\section{Declarations}

\section{Acknowledgments}

The authors express their gratitude and appreciation to the deputy of the Tehran University of Medical Sciences and the officials and staff of the health centers of Tehran University of Medical Sciences.

\section{Funding}

No funding was obtained for this study. 


\section{Author information}

\section{Affiliations}

Department of Cardiology, Tehran Heart Center, School of Medicine, Tehran University of Medical Sciences, Tehran, Iran.

\section{Contributions}

A.A. was responsible for the study design and manuscript writing. SH.S. was responsible for the recruitment of participants and data collection. F.KH was responsible for analyzed and interpreted the data and manuscript writing. M.R. interpreted the data, and reviewed the manuscript. N.O. designed the study and manuscript writing, is the guarantor of this work and, as such, had full access to all the data in the study and takes responsibility for the integrity of the data and the accuracy of the data analysis. All authors have read and approved the manuscript.

\section{Corresponding author}

Correspondence to Negar Omidi.

\section{Ethics approval and consent to participate}

The present study is part of a thesis to receive the Ph.D. certificate of family physician, all participants signed written informed consent forms and the trial was approved by the ethics committee of the Tehran University of Medical Sciences, RIES affiliated to the Tehran University of Medical Sciences.

IR.TUMS.MEDICINE.REC.1396.3071.

\section{Consent for publication}

None required.

\section{Availability of data and material}

All data generated or analyzed during this study are included in this published article [and its supplementary information files].

\section{Competing interests}

No conflicting financial interests exist.

\section{References}

1. Saklayen, M.G., The Global Epidemic of the Metabolic Syndrome. Curr Hypertens Rep, 2018. 20(2): p. 12.

2. Dunkley, A.J., et al., Effectiveness of interventions for reducing diabetes and cardiovascular disease risk in people with metabolic syndrome: systematic review and mixed treatment comparison meta-analysis. Diabetes Obes Metab, 2012. 14(7): p. 616-25. 
3. Annani-Akollor, M.E., et al., Prevalence of metabolic syndrome and the comparison of fasting plasma glucose and HbA1c as the glycemic criterion for MetS definition in non-diabetic population in Ghana. Diabetol Metab Syndr, 2019. 11: p. 26.

4. Kalan Farmanfarma, K., et al., Prevalence of metabolic syndrome in Iran: A meta-analysis of 69 studies. Diabetes Metab Syndr, 2019. 13(1): p. 792-799.

5. Amirkalali, B., et al., Prevalence of Metabolic Syndrome and Its Components in the Iranian Adult Population: A Systematic Review and Meta-Analysis. Iran Red Crescent Med J, 2015. 17(12): p. e24723.

6. Dalvand S, Niksima SH, Meshkani R, et al. Prevalence of Metabolic Syndrome among Iranian Population: A Systematic Review and Meta-analysis. Iran J Public Health. 2017;46(4):456-467. PMID: 28540261; PMCID: PMC5439034.

7. Khosravi-Boroujeni, H., et al., Secular Trend of Metabolic Syndrome and Its Components in a Cohort of Iranian Adults from 2001 to 2013. Metab Syndr Relat Disord, 2017. 15(3): p. 137-144.

8. Mazloomzadeh S, Rashidi Khazaghi Z, Mousavinasab N. The Prevalence of Metabolic Syndrome in Iran: A Systematic Review and Meta-analysis. Iran J Public Health. 2018;47(4):473-480. PMID: 29900131; PMCID: PMC5996331.

9. Ostovar, R., et al., Prevalence of metabolic syndrome in Iran: A meta-analysis. Electron Physician, 2017. 9(10): p. 5402-5418.

10. Jeon, S.W., et al., Metabolic syndrome and incident depressive symptoms in young and middle-aged adults: A cohort study. J Affect Disord, 2019. 246: p. 643-651.

11. Perez-Martinez, P., et al., Lifestyle recommendations for the prevention and management of metabolic syndrome: an international panel recommendation. Nutr Rev, 2017. 75(5): p. 307-326.

12. Wang, Q., et al., Metabolic Syndrome Knowledge among Adults with Cardiometabolic Risk Factors: A Cross-Sectional Study. International journal of environmental research and public health, 2019. 16(1): p. 159.

13. Bjørnnes, A.K., et al., The impact of an educational pain management booklet intervention on postoperative pain control after cardiac surgery. European Journal of Cardiovascular Nursing, 2017. 16(1): p. 18-27.

14. Yoo, S., H. Kim, and H.I. Cho, Improvements in the metabolic syndrome and stages of change for lifestyle behaviors in korean older adults. Osong Public Health Res Perspect, 2012. 3(2): p. 85-93.

15. Bassi, N., et al., "Lifestyle modification for metabolic syndrome: a systematic review.". Am J Med. 2014 Dec;127(12):1242.e1-10.

16. Azizi, F., et al., The effect of community-based education for lifestyle intervention on the prevalence of metabolic syndrome and its components: tehran lipid and glucose study. Int J Endocrinol Metab, 2013. 11(3): p. 145-53.

17. Gurusamy, J., et al., Exercise, diet and educational interventions for metabolic syndrome in persons with schizophrenia: A systematic review. Asian J Psychiatr, 2018. 36: p. 73-85.

18. Jahangiry, L., et al., An interactive web-based intervention on nutritional status, physical activity and health-related quality of life in patient with metabolic syndrome: a randomized-controlled trial (The Red 
Ruby Study). Nutr Diabetes, 2017. 7(1): p. e240.

19. Kastorini, C.M., et al., The effect of Mediterranean diet on metabolic syndrome and its components: a meta-analysis of 50 studies and 534,906 individuals. J Am Coll Cardiol, 2011. 57(11): p. 1299-313.

20. Yamaoka, K. and T. Tango, Effects of lifestyle modification on metabolic syndrome: a systematic review and meta-analysis. BMC Med, 2012. 10: p. 138.

21. Ghasemi, A., et al., New modified Friedewald formulae for estimating low-density lipoprotein cholesterol according to triglyceride levels: extraction and validation. Endocrine, 2018. 62(2): p. 404-411.

22. Arnett, D.K., et al., 2019 ACC/AHA Guideline on the Primary Prevention of Cardiovascular Disease: Executive Summary: A Report of the American College of Cardiology/American Heart Association Task Force on Clinical Practice Guidelines. Circulation, 2019. 140(11): p. e563-e595.

23. Amiri, P., et al., The Effects of a Community-Based Lifestyle Intervention on Metabolic Syndrome and Its Components in Adolescents: Findings of a Decade Follow-Up. Metab Syndr Relat Disord, 2018. 16(5): p. 215-223.

24. Chaiyasoot, K., et al., Evaluation of a 12-week lifestyle education intervention with or without partial meal replacement in Thai adults with obesity and metabolic syndrome: a randomised trial. Nutr Diabetes, 2018. 8(1): p. 23.

25. Dalle Grave, R., et al., Lifestyle modification in the management of the metabolic syndrome: achievements and challenges. Diabetes Metab Syndr Obes, 2010. 3: p. 373-85.

26. Jane, M., et al., Effects of a weight management program delivered by social media on weight and metabolic syndrome risk factors in overweight and obese adults: A randomised controlled trial. PLoS One, 2017. 12(6): p. e0178326.

27. Admiraal, W.M., et al., Intensive lifestyle intervention in general practice to prevent type 2 diabetes among 18 to 60-year-old South Asians: 1-year effects on the weight status and metabolic profile of participants in a randomized controlled trial. PLoS One, 2013. 8(7): p. e68605.

28. Islam, N.S., et al., Diabetes prevention in the New York City Sikh Asian Indian community: a pilot study. Int J Environ Res Public Health, 2014. 11(5): p. 5462-86.

29. Martin, C.A., et al., Systematic Review of the Effect of Lifestyle Interventions on the Components of the Metabolic Syndrome in South Asian Migrants. J Immigr Minor Health, 2018. 20(1): p. 231-244.

30. Bhopal, R.S., et al., Effect of a lifestyle intervention on weight change in south Asian individuals in the UK at high risk of type 2 diabetes: a family-cluster randomised controlled trial. Lancet Diabetes Endocrinol, 2014. 2(3): p. 218-27.

31. Telle-Hjellset, V., et al., The InnvaDiab-DE-PLAN study: a randomised controlled trial with a culturally adapted education programme improved the risk profile for type 2 diabetes in Pakistani immigrant women. Br J Nutr, 2013. 109(3): p. 529-38.

32. Madero, M., et al., A pilot study on the impact of a low fructose diet and allopurinol on clinic blood pressure among overweight and prehypertensive subjects: a randomized placebo controlled trial. J Am Soc Hypertens, 2015. 9(11): p. 837-44.

33. Rossi, R.C., et al., Impact of obesity on autonomic modulation, heart rate and blood pressure in obese young people. Auton Neurosci, 2015. 193: p. 138-41. 
34. Bustos, P., et al., [Effects of the Bright Bodies Program in Chilean obese children]. Rev Med Chil, 2015. 143(9): p. 1136-43.

35. Elizondo-Montemayor, L., et al., School-based individualised lifestyle intervention decreases obesity and the metabolic syndrome in Mexican children. J Hum Nutr Diet, 2013. 26 Suppl 1: p. 82-9.

36. Ashizawa, E., et al., [Use of a pamphlet to encourage individuals to eat slowly to help reduce the development of metabolic syndrome]. Sangyo Eiseigaku Zasshi, 2019. 61(1): p. 9-15.

37. Watanabe, M., et al., Effects of a lifestyle modification programme to reduce the number of risk factors for metabolic syndrome: a randomised controlled trial. Public Health Nutr, 2017. 20(1): p. 142-153.

\section{Tables}

Table 1: Baseline characteristics of study participants

\begin{tabular}{|c|c|c|c|}
\hline \multirow[t]{2}{*}{ Variable } & Intervention group & control group & \multirow[t]{2}{*}{$p$} \\
\hline & $(n=34)$ & $(n=36)$ & \\
\hline Age $($ mean $\pm S D)$ & $43.6 \pm 9.9$ & $47.9 \pm 7.5$ & 0.044 \\
\hline Sex (\% male) & 25.0 & 33.3 & 0.437 \\
\hline Married (\%) & 97.2 & 100 & 0.5 \\
\hline Education: & & & 0.021 \\
\hline$<$ College degree $(\%)$ & 58.3 & 86.1 & \\
\hline$\geq$ College degree $(\%)$ & 41.7 & 13.9 & \\
\hline Smoking (\% yes) & 2.8 & 0.0 & 0.5 \\
\hline Drug user (\% yes) & 2.8 & 0.0 & 0.5 \\
\hline
\end{tabular}

Table 2 : Anthropometric and metabolic profile of groups over the time

\begin{tabular}{lcccccc}
\hline \multirow{2}{*}{ Variable } & \multicolumn{3}{c}{ Intervention group $(\mathrm{n}=34)$} & \multicolumn{3}{c}{ control group (n=36) } \\
\cline { 2 - 7 } & Baseline & 3 month & $\mathrm{p}$ & Baseline & 3 month & $\mathrm{p}$ \\
\hline Weight (kg) & $82.3 \pm 13.6$ & $80.3 \pm 14$ & $<0.001$ & $80.7 \pm 11.5$ & $80.8 \pm 11.9$ & 0.671 \\
\hline waist circumference (cm) & $102 \pm 8.8$ & $99.7 \pm 7.9$ & $<0.001$ & $102.4 \pm 6$ & $103 \pm 6.3$ & 0.061 \\
\hline Hip Circumference(cm) & $111.5 \pm 10.2$ & $110.1 \pm 10.5$ & $<0.001$ & $108.8 \pm 7.7$ & $109 \pm 8.3$ & 0.513 \\
\hline Waist-hip ratio & $0.92 \pm 0.06$ & $0.90 \pm 0.06$ & 0.042 & $0.94 \pm 0.06$ & $0.95 \pm 0.05$ & 0.237 \\
\hline SBP* (mm/Hg) & $118.7 \pm 18.3$ & $114.7 \pm 16$ & 0.06 & $121.8 \pm 20.4$ & $118.8 \pm 17.6$ & 0.166 \\
\hline DBP** (mm/Hg) & $78.4 \pm 10.6$ & $73.1 \pm 9.2$ & $<0.001$ & $77.2 \pm 9.9$ & $76.4 \pm 7.9$ & 0.433 \\
\hline MAP & $91.8 \pm 12.3$ & $86.9 \pm 11.1$ & $<0.001$ & $92.1 \pm 12.6$ & $90.5 \pm 10.5$ & 0.206 \\
\hline FBS (mg/dL) & $103.3 \pm 15.1$ & $104.1 \pm 10.5$ & 0.746 & $125.2 \pm 44.2$ & $125.7 \pm 46.5$ & 0.872 \\
\hline Cholesterol (mg/dL) & $186.4 \pm 33$ & $178.6 \pm 32.7$ & 0.168 & $191.1 \pm 33.2$ & $179.5 \pm 31.7$ & 0.102 \\
\hline Triglyceride(mg/dL) & $172.1 \pm 76.7$ & $138.5 \pm 56.8$ & 0.002 & $216.2 \pm 116.1$ & $177.9 \pm 72.3$ & 0.043 \\
\hline HDL*** (mg/dL) & $40.2 \pm 6.8$ & $43.5 \pm 8.1$ & 0.012 & $40.6 \pm 6.8$ & $42.6 \pm 6.7$ & 0.048 \\
\hline LDL**** (mg/dL) & $114.2 \pm 27.1$ & $106.8 \pm 28.9$ & 0.132 & $104.3 \pm 30.6$ & $101.8 \pm 27.9$ & 0.697 \\
\hline Data are presented as mean \pm SD & & & & & \\
\hline
\end{tabular}


SBP: Systolic blood pressure; DBP: Diastolic blood Pressure; HDL: High-density Lipoprotein; LDL: Low-density Lipoprotein; MAP: mean arterial pressure

Table 3 : Prediction the effect of intervention on metabolic syndrome components

\begin{tabular}{llll}
\hline Variable & F & Partial Eta Squared & Sig. ${ }^{*}$ \\
\hline Diff waist circumference & 23.27 & 0.258 & $<0001$ \\
\hline Diff SBP & 0.08 & 0.001 & 0.773 \\
\hline Diff DBP & 8.29 & 0.11 & 0.005 \\
\hline Diff FBS & 0.06 & 0.001 & 0.810 \\
\hline Diff TG & 0.01 & 0 & 0.931 \\
\hline Diff HDL & 0.63 & 0.009 & 0.429 \\
\hline
\end{tabular}

Note: ${ }^{*} p<0.05$

SBP: systolic blood pressure; DBP: diastolic blood pressure; FBS: fasting blood glucose; TG: triglyceride; HDL: high density lipoprotein

\section{Appendices}

Appendix 1- Educational Package for Controlling Metabolic Syndrome Components in intervention group 


\begin{tabular}{|c|c|c|c|}
\hline Duration & First month & Second month & Third month \\
\hline $\begin{array}{l}\text { Educational } \\
\text { method }\end{array}$ & $\begin{array}{l}\text { Face-to-Face education and } \\
\text { pamphlets }\end{array}$ & Virtual education & Educational film \\
\hline $\begin{array}{l}\text { Intervention } \\
\text { description }\end{array}$ & $\begin{array}{l}\text { Face-to-face education Focusing on } \\
\text { metabolic syndrome, the prevalence } \\
\text { and importance of its risk factors, } \\
\text { and its therapeutic prevention } \\
\text { recommendations. Moreover, the } \\
\text { participants were encouraged to } \\
\text { lose weight appropriate physical } \\
\text { activity, and avoiding smoking. } \\
\text { The duration of the first phase of } \\
\text { education was about } 15 \text { minutes. } \\
\text { The sessions were held in the } \\
\text { physician's office. } \\
\text { Pamphlets, for covering lifestyle } \\
\text { modification issues which were } \\
\text { taughtduring face-to-face education } \\
\text { program }\end{array}$ & $\begin{array}{l}14 \text { educational messages were } \\
\text { sent to the subjects in the } \\
\text { intervention group in the first } 5 \\
\text { days of each week based on } \\
\text { knowledge, attitude, and } \\
\text { performance in preventing the } \\
\text { metabolic syndrome components. }\end{array}$ & $\begin{array}{l}\text { The educational films ( } 15 \text { minutes) were } \\
\text { held in the comprehensive health center } \\
\text { classroom. }\end{array}$ \\
\hline $\begin{array}{l}\text { Intervention } \\
\text { goals }\end{array}$ & $\begin{array}{l}\text { Improving' knowledge, attitude, and } \\
\text { behaviors regarding healthy dietary } \\
\text { habits, appropriate physical activity, } \\
\text { and avoiding smoking } \\
\text { - Motivating to modify their } \\
\text { unhealthy behaviors } \\
\text { - Creating a supportive environment } \\
\text { to encourage healthy behaviors } \\
\text { among } \\
\text { - Reducing rate of NCDs }\end{array}$ & $\begin{array}{l}\text { The text messages aimed to } \\
\text { increase the health literacy } \\
\text { remind and increase the } \\
\text { motivation of individuals. The } \\
\text { messages also tried to make } \\
\text { recommendations in order to } \\
\text { have a healthy lifestyle and } \\
\text { provide metabolic syndrome } \\
\text { education programs. } \\
\text { The transmission of these } \\
\text { messages to a wide range of } \\
\text { people in the community can } \\
\text { prevent cardiovascular disease } \\
\text { and diabetes to a large extent. }\end{array}$ & $\begin{array}{l}\text { Aimed to promote and encourage the } \\
\text { individuals, better understand the } \\
\text { learning, increase the amount of } \\
\text { memorization of materials, and transfer } \\
\text { the shared experiences about the } \\
\text { metabolic syndrome components, related } \\
\text { diseases, methods of diagnosis, and } \\
\text { control and prevention by lifestyle } \\
\text { modification. }\end{array}$ \\
\hline
\end{tabular}

Appendix 2- Practical recommendations for diet and physical exercise in lifestyle modification [38]

\section{Dietary recommendations}

Encouraged overweight and obese individuals to lose weight by $5-10 \%$ and adopt healthy eating habits by increasing the consumption of fresh fruits and vegetables by more than 2 to 3 units per day, whole grains and seeds, beans, white meat and fish, nuts and low-fat dairy products, and not using unsaturated fats such as solid and animal oils and butter, and replacing them with liquid vegetable oils, as well as reducing the consumption of frying food, fast food, consuming a diet with restricted amount of sugar, sweetmeat, starch, and red meat products. This study emphasized on reducing the consumption of salt up to 2 teaspoons per day and not using the saltshaker in setting the table and replacing salt with food additive in controlling blood pressure based on the 2016 European Guideline on Cardiovascular Diseases Primary Prevention. Additionally, the individuals older than 18 years were recommended to schedule yearly regular checkups and do the required tests at the physician discretion.

Recommended to do moderate to severe physical activity for at least 30 minutes, 3 to 5 times a week. 


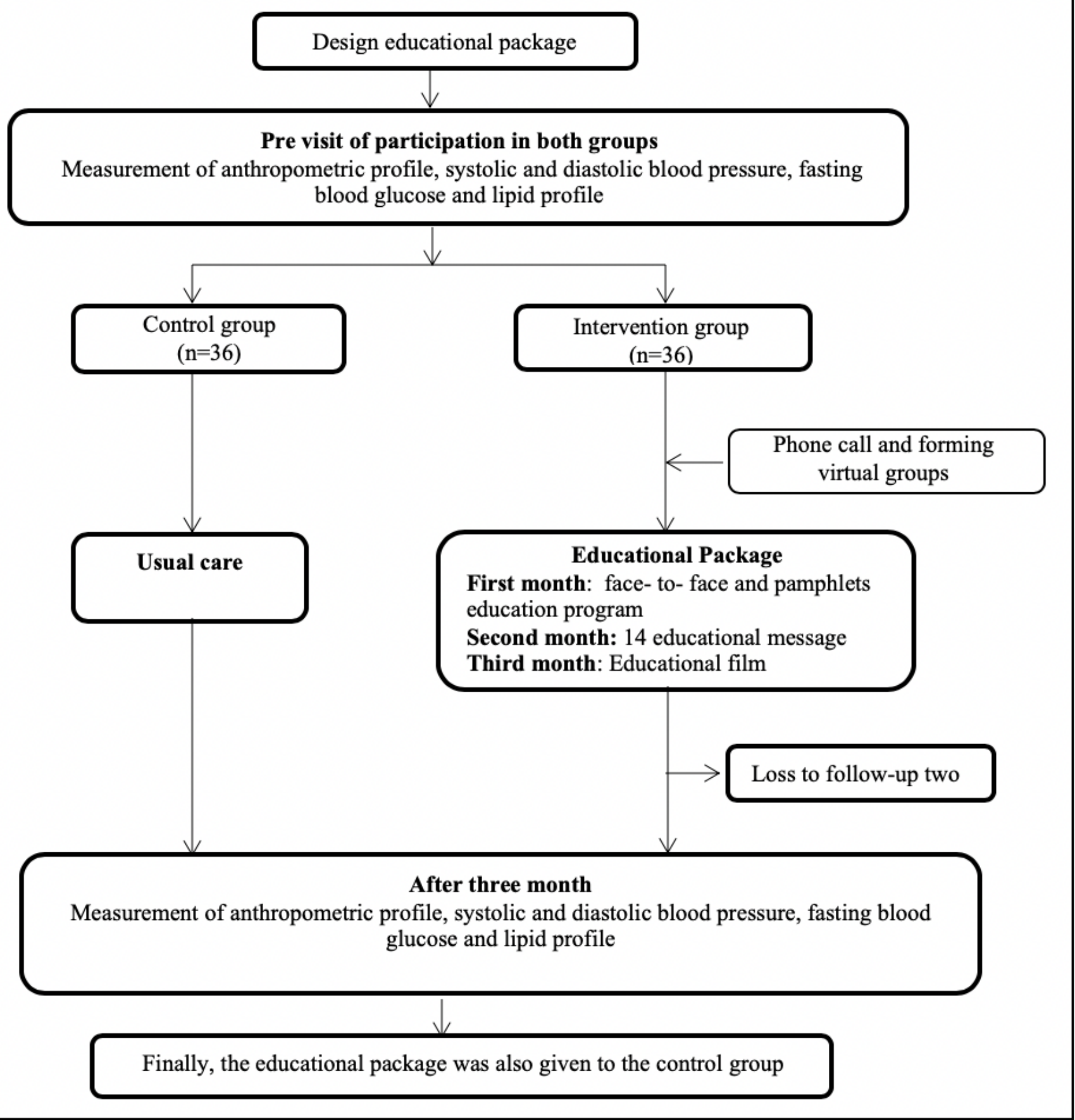

Figure 1

study-design chart

\section{Supplementary Files}

This is a list of supplementary files associated with this preprint. Click to download. 